\title{
TRANSFERÊNCIA COMPULSÓRIA NO REGIMENTO ESCOLAR: UM PROCESSO DE EXCLUSÃO NA EDUCAÇÃO BÁSICA
}

\section{Compulsory transfer in school regulation: a process of exclusion in basica education}

\author{
Maria Lucia Morrone - Universidade Ibirapuera/Brasil
}

RESUMO: O artigo demonstra que a transferência compulsória pode incidir em sanção punitiva, interferindo no processo educativo, que é função social da escola. A metodologia baseia-se em publicações científicas, jurídicas e legislação vigente. Com relação a transferência compulsória, a escola não deve reforçar o ato punitivo mas cumprir o seu papel social enquanto instituição que se propõe a educar para a cidadania e não apenas ao ensino/aprendizagem. Defende-se também que mediante a aplicação dessa medida, em hipótese alguma deverá permanecer fora do contexto escolar, até o julgamento final do recurso, se este for impetrado pelo aluno, pais ou responsáveis, evitando-se situações de constrangimento e exclusão. Como considerações finais, afirmase que, se não houver o sistemático acompanhamento do aluno, a sua transferência compulsória, pode excluí-lo de seu direito à permanência na educação básica.

Palavras-chave: Exclusão educacional. Função socioeducativa da escola. Permanência no sistema escolar. Transferência compulsória.

ABSTRACT: The article demonstrates that compulsory transfer can be punitive, interfering with the educational process, which is the social function of the school. The methodology is based on scientific publications, legal and current legislation. It is also argued that by applying this measure, under no circumstances should remain outside the school context, until the final judgment of the appeal, if it is filed by the student, parents or guardians, avoiding situations of embarrassment and exclusion. At final considerations, it is stated that if there is no systematic monitoring of the student, his compulsory transfer may exclude him from his right to remain in basic educational.

Keywords: Compulsory transfer. Educational exclusion. Permanence in the school system. Socioeducational function of the school.

\section{INTRODUÇÃO}

Em consonância com o tema direitos humanos e inclusão socioeducativa do educando, este artigo analisa a transferência compulsória inserida no Regimento Escolar da Educação Básica, tendo por hipótese que a aplicação dessa sanção disciplinar, tende a um impasse, porque, em geral, prevalece a tendência punitiva sobre a educacional, na medida em que pode incidir na exclusão do direito do aluno à permanência no sistema escolar o qual tem por finalidade precípua a formação integral e humanística para o 
desenvolvimento de sua cidadania responsável e participativa, na sociedade em que está inserido.

A comunidade escolar, na maioria dos casos, ao considerar, a transferência compulsória, prioritariamente, como um processo educativo no ensino/aprendizagem, sem o imprescindível acompanhamento do aluno, por integrantes da comunidade escolar, que deve ser exercido pelos gestores( supervisores, diretores e vice-diretores), docentes e pais ou responsáveis, a aplicação dessa sanção disciplinar tende geralmente, a valorizar sua dimensão punitiva sobre a educacional, culminando, efetivamente, com a exclusão do aluno da educação básica. Torna-se fundamental o resgate da função social da escola, a partir de uma educação dialógica e emancipadora à formação da cidadania e de que essa medida disciplinar não seja o instrumento primordial e exclusivo à responsabilização do aluno, assim como, pressupõe-se a ilegalidade da mesma, tendo em vista a garantia constitucional do direito ao acesso e à permanência do aluno na escola.

A Constituição da República Federativa de 1988 destaca os "direitos fundamentais do cidadão: a vida, a liberdade, a igualdade, a segurança e a propriedade" (Art. 5) definindo a Educação como um direito social, "direito de todos e dever do Estado e da família" e ratifica que "será promovida e incentivada com a colaboração da sociedade" (Art. $\left.6^{\circ}\right)$.

De acordo com a Carta Magna, portanto, a Educação é "direito de todos, dever do Estado e da família que será promovido e incentivada com a colaboração da sociedade, visando ao pleno desenvolvimento da pessoa, seu preparo para o exercício da cidadania e qualificação para o trabalho" (Art. 205).

Com o objetivo de conceder eficácia à educação, a Constituição Federal estabeleceu os princípios da "igualdade de condições para o acesso e permanência na escola" (inciso I do Art. 206) ou seja, a criança e o adolescente tem o direito de ingressar na escola e nela permanecer, sem distinção de qualquer natureza. Esses princípios constitucionais estão reafirmados no Art. 53 do ECA "A criança e o adolescente têm direito à educação, visando ao pleno desenvolvimento de sua pessoa, preparo e exercício da cidadania e qualificação para o trabalho", assegurando no inciso I do mesmo artigo a "Igualdade de condições para o acesso e permanência na escola".

A LDBEN/96 reafirma que o ensino será ministrado com base nos princípios de "Igualdade de condições para o acesso e permanência na escola" (Art. $3^{\circ}$ - Inciso I). 
Prescreve que "Os estabelecimentos de ensino, respeitadas as normas comuns e as do seu sistema de ensino, terão a incumbência de elaborar e executar sua proposta pedagógica" (Art. 12 - Inciso I). Determina ainda que "Os sistemas de ensino assegurarão às unidades escolares públicas de educação básica que os integram, progressivos graus de autonomia pedagógica e administrativa e de gestão financeira, observadas as normas gerais de direito financeiro público" (LDBEN/96 Art. 15).

Com relação a essa autonomia pedagógica dos estabelecimentos de ensino, evidencia-se que devem ser, "respeitadas as normas comuns e as do seu sistema de ensino" sem deixar de destacar a elaboração e execução da proposta pedagógica, e aqui se enfatiza a necessária participação da comunidade escolar, para fundamentar a construção do Regimento Escolar. A autonomia no contexto educacional, precisa ser compreendida como a ação que

\begin{abstract}
(...) transforma a realidade e não a contemplação. As ideias não têm valor por si próprias, mas por sua capacidade de impulsionar a ação para promover resultados desejados. E estas devem ser monitoradas e avaliadas, a fim de que se possa evidenciar ao público os seus resultados e se ter parâmetros para o prosseguimento das ações. $\mathrm{O}$ desenvolvimento da escola e a realização de seu trabalho têm um rumo, propõem a realização de objetivos e, para tanto, há a necessidade de definição clara e objetiva de seus resultados finais e intermediários, que devem ser acompanhados e avaliados, visando à necessária correção, quando for o caso; o cuidado com o ritmo de trabalho, que deve se manter constante; a identificação de problemas a serem contornados; o uso adequado de recursos; o estabelecimento da relação custo-benefício e a identificação de novas perspectivas de ação [...]. (LUCK, 2000, p.28)
\end{abstract}

Defende-se a tese de que a educação deve ser transformadora por excelência, por meio do conhecimento acumulado e difundido na relação pedagógica entre o docente e aluno, e, ao mesmo tempo, construído nos diferentes contextos históricos. A força transformadora da educação ambienta-se no espaço escolar como projeção das experiências relacionais entre educadores, pais ou responsáveis e alunos, assim como da comunidade escolar com o mundo em seu entorno.

São essas experiências e vivências diárias que permitem desenvolver a alteridade, ou seja, perceber o lugar do outro, a existência de limites - por vezes flexibilizados no contexto familiar -, e a tolerância com o próximo que não compartilha os mesmos valores. Torna-se necessário o desenvolvimento da percepção de que, no espaço escolar, o respeito

Educação, Psicologia e Interfaces, Volume 3, Número 3, p. 48-63, Setembro/Dezembro, 2019. 
é a condição, de início, meio e fim, para que cada um exercite, no coletivo, a sua individualidade.

Os conflitos que fazem parte da natureza humana devem ser compreendidos como oportunidades de mudanças e crescimento. Eles estão presentes nas escolas, espaços privilegiados para a disseminação de valores à construção da cidadania responsável e participativa. A comunidade escolar constituída pelos gestores, corpo docente e discente, pais ou responsáveis e funcionários, precisa conhecer coletivamente, procedimentos pedagógicos que possibilitem o seu gerenciamento pacífico, à prevenção e superação desses conflitos, contribuindo para o desenvolvimento de relações no espaço escolar, priorizando o desenvolvimento de valores humanísticos, essenciais à formação das crianças e jovens, entre os quais, o respeito, a alteridade, a interconexão, a responsabilidade social e a autodisciplina.

A escola apresenta uma diversidade de conflitos, sobretudo os de relacionamento, pois nela convivem pessoas que apresentam diferenciação de idades cronológicas, origens sociais, sexos, etnias e condições socioeconômicas e culturais. Todos os envolvidos na comunidade escolar devem estar preparados para o enfrentamento da heterogeneidade, das diferenças e das tensões próprias da convivência escolar, que muitas vezes podem gerar dissenso e desarmonia. A escola tem por função social formar valores e habilidades para a convivência e deve prever em seu Projeto Pedagógico, ações para a superação de conflitos que nela ocorrem.

$\mathrm{Na}$ escola, o processo ensino/aprendizagem deve estar direcionado ao trabalho preventivo de reafirmação das relações, visando aperfeiçoar o relacionamento escolafamília-comunidade, por meio do diálogo, tendo por finalidade a compreensão e o respeito às diferenças individuais para que possam ser consolidados os vínculos entre os integrantes da comunidade escolar. Desta forma, o processo ensino/aprendizagem tem por objetivo educacional a consolidação da comunidade escolar democrática e o fortalecimento de uma cultura de paz.

\section{MATERIAL E MÉTODO}

Fundamenta-se em autores cujas obras científicas destacam a importância e diretrizes da educação participativa e dialógica para a criança e adolescente, entre outras, como a de Hannah Arendt (1972), Sacristán (1998) Paulo Freire (2016), na publicação 
jurídica do Conselho Nacional do Ministério Público (2014) que aborda os dilemas da transferência compulsória, assim como, na legislação vigente que prescreve o direito ao acesso e permanência do estudante na educação básica: Constituição da República Federativa do Brasil de 1988; a Lei de Diretrizes e Bases da Educação Nacional (LDBEN) 9.394/96; o Estatuto da Criança e do Adolescente (ECA) (BRASIL,1990); Indicação 175/2019 do Conselho Estadual da Educação (CEE) do Estado de São Paulo que estabelece a "transferência por questões disciplinares como medida educativa de caráter excepcional".

\section{FUNDAMENTOS FILOSÓFICOS E PSICOLÓGICOS DO PROCESSO EDUCACIONAL}

A educação é a construção contínua do ser humano e a integração de todas as dimensões da nossa vida: do cognitivo, de valores, das aptidões, habilidades, da capacidade de discernimento e de ação. Educar é contribuir para o aperfeiçoamento intelectual, profissional e emocional do ser humano. Para dar respostas aos grandes desafios da educação no mundo contemporâneo, em 1993 a Organização das Nações Unidas para a Educação, Ciência e Cultura (UNESCO) ${ }^{1}$, criou uma Comissão Internacional sobre Educação para o atual século XXI, presidida por Jacques Delors. A Comissão produziu um relatório com sugestões e recomendações, que passou a ser conhecido como Relatório Delors, e que ganhou o status de agenda para políticas públicas na área da educação em todo o mundo.

O Relatório defende a organização da educação com base em quatro princípios denominados pilares do conhecimento, os quais interagem e são interdependentes, relacionados a um amplo conceito de educação, contemplando o ser humano de forma holística, ou seja, em sua totalidade e em suas relações sociais. Os quatro pilares foram caracterizados como: aprender a conhecer; aprender a fazer; aprender a ser e aprender a conviver. A educação segundo esse Relatório é concebida como integral, que vai além dos limites da sala de aula e extrapola o processo permanente de enriquecimento dos conhecimentos, numa diretriz de formação da própria pessoa, das relações entre indivíduos, grupos e nações.

A partir desses pilares, a escola precisa ensinar a importância do diálogo, o que pressupõe preparar as crianças e os jovens ao desenvolvimento de uma personalidade

Educação, Psicologia e Interfaces, Volume 3, Número 3, p. 48-63, Setembro/Dezembro, 2019.

ISSN: 2594-5343. DOI: https://doi.org/10.37444/issn-2594-5343.v3i3.165 
Transferência compulsória no regimento escolar: um processo de exclusão na educação básica

equilibrada, ao aprendizado das relações interpessoais, sobretudo por meio de comunicação dialógica e à compreensão das diferenças interculturais e à cultura da não violência.

Além desses pilares da educação segundo o Relatório Delors, não se pode deixar de mencionar a Base Nacional Curricular Comum (BNCC) da Educação Básica, aprovada em 2017, para a Educação Infantil e Ensino Fundamental ${ }^{2}$ que passa a ser uma referência nacional aos entes federados ${ }^{3}$ para os processos de elaboração de currículos e materiais didáticos, assim como, às políticas de formação inicial e continuada de gestores e docentes. A BNCC destaca dez competências que devem ser desenvolvidas ao longo da Educação Básica, “conhecimento; pensamento científico, crítico e criativo; repertório cultural; comunicação; cultura digital; trabalho e projeto de vida, argumentação e autoconhecimento e autocuidado". O desenvolvimento dessas competências, concordese ou não, com as mesmas, deve, contudo, priorizar o objetivo educacional à formação da cidadania responsável, crítica e participativa, assim como, à cultura da relação dialógica e da não violência.

A abordagem sobre a cultura da não violência, refere-se ao respeito à vida, ao fim de qualquer modalidade de violência, à cultura do diálogo e da solução pacífica dos conflitos, ao respeito à dignidade da pessoa humana e ao compromisso com os direitos humanos. Para tanto, o processo ensino/aprendizagem deve viabilizar mudanças diretas no campo das inter-relações, conduzindo os envolvidos à inclusão colaborativa, que resgata o diálogo, a conexão com o próximo e a comunicação entre os agentes escolares, familiares, comunidades e redes de apoio.

O processo ensino/aprendizagem deve contribuir para lidar com os conflitos de forma diferenciada, ou seja, desafiando os tradicionais padrões punitivos. Compreendese os conflitos como oportunidades de mudança e de aprendizagem, ressaltando os valores da inclusão, do pertencimento, da escuta ativa e da solidariedade. São mudanças de modelos de cultura, de paradigmas e de práticas que permitem a construção de cultura de paz nas escolas.

Portanto, tendo por objetivo educacional em seu Projeto Pedagógico a formação para o exercício da cidadania, a escola não pode prever sanções de exclusão do aluno, o que seria, no mínimo, contraditório com o processo educativo que é a sua função social. Transferir compulsoriamente entende-se como transferir o problema sem solucioná-lo. É 
compreensível que a escola cumpra seu papel de educadora e disciplinadora, mas dialogicamente, respeitando e apoiando o educando, para que este se sinta pertencente à comunidade escolar, retribuindo à mesma, atitudes de respeito e alteridade.

\section{DIAGNÓSTICO DOS CONFLITOS NO CONTEXTO ESCOLAR NO PERÍODO DE 2014-2015}

Uma pesquisa realizada pela Faculdade Latino-Americana de Ciências Sociais (Flacso), em parceria com o Ministério da Educação e a Organização dos Estados Interamericanos (OEI), revelou que no período de 2014 a 2015, a violência verbal ou física atingiu $42 \%$ dos alunos da rede pública. Esta é a primeira edição da pesquisa que, entre janeiro e novembro de 2015, ouviu 6.709 estudantes, de 12 a 29 anos, em sete capitais brasileiras: Maceió, Fortaleza, Vitória, Salvador, São Luís, Belém e Belo Horizonte. Todas elas apresentaram, segundo o Mapa da Violência de 2014, taxas de homicídio maiores entre os jovens (82,7 homicídios por 100 mil jovens).

O estudo considerou violência não apenas as agressões físicas e homicídios, fatos que, apesar de existirem, são menos recorrentes. Discriminação, ameaças e "xingamentos", muitas vezes confundidos com brincadeiras, também foram identificados como atos violentos que poderiam evoluir para agressões mais graves, tornando o ambiente escolar hostil.

De acordo com $70 \%$ dos alunos, houve algum tipo de violência na escola em que estudaram no último ano. Entre os violentados, $65 \%$ apontaram um colega como agressor. Mais de $15 \%$ alegaram que a agressão partiu dos próprios professores. Entre os tipos de violência praticada, o cyberbullying - que engloba intimidações na internet e em aplicativos de conversa - representou $28 \%$ dos casos. Roubo e furto representaram $25 \%$ e ocorrências de ameaças, $21 \%$.

Para a socióloga Míriam Abramovay, coordenadora da pesquisa, um dos dados mais chocantes foi a identificação sobre o local onde mais ocorreram os episódios violentos. Na sala de aula, que deveria ser um lugar protegido e propício ao ensino/aprendizagem, constatou 25\% das ocorrências, o mesmo percentual nos pátios, e, nos corredores $22 \%$.

A pesquisa foi realizada em duas etapas. Na primeira, estudantes de 140 escolas públicas sorteadas responderam a questionários que originaram os dados percentuais acima descritos. A segunda etapa foi desenvolvida pelos próprios alunos, a partir de um 
diagnóstico participativo, assim chamado pelo estudo. Cerca de 10 jovens por escola foram orientados por professores para pontuar em "cadernos de campo" as características do cotidiano escolar. O objetivo era torná-los pesquisadores de sua própria realidade. A socióloga afirma que “(...) Os jovens têm um olhar especial sobre suas escolas, o que, muitas vezes, adultos e pesquisadores não têm” (ABRAMOVAY, Miriam,2016).

A pesquisa evidenciou a importância de se considerar não somente os episódios identificados como violentos, mas também a infraestrutura da escola. As salas de aulas quentes, sem iluminação e superlotadas foram apontadas pelos alunos como responsáveis por tornar o ambiente escolar propício para o surgimento de conflitos.

A pesquisadora constatou que (...) "Infraestrutura, conjunto de regras da instituição e relações interpessoais constituem o chamado clima escolar, que, quando deficitário, interfere nas taxas de violência” (...).

Com 15 anos de experiência em pesquisas sobre violência nas escolas, a socióloga relaciona os conflitos e os indicadores de violência que ocorrem no cotidiano escolar à dificuldade que as instituições têm de se adequar à realidade e às necessidades dos alunos. "A escola continua seguindo um modelo do século retrasado. Ela não é feita para esses alunos, não tem a ver com o que eles querem e pensam" (ABRAMOVAY, 2016).

O diagnóstico dos conflitos escolares com a participação do estudante é uma forma de superá-los no contexto escolar. Quando os estudantes debruçam sobre seu cotidiano - e registram o que observam - passam a exercitar o senso crítico e a ampliar a visão sobre o que é violência, com seus fatores e consequências. Para Míriam Abramovay (2016) “O objetivo é mostrar que jovens podem opinar, participar e ajudar na solução dos problemas da escola".

Pela pesquisa citada conclui-se que a má adequação da infraestrutura da escola contribui para disseminar os conflitos e que antes de serem tomadas as medidas disciplinares previstas no Regimento Escolar essa situação deve ser considerada, especialmente no caso da transferência compulsória, a qual poderá se tornar uma medida excludente. $\mathrm{O}$ direito de acesso e permanência na escola é medida de proteção à criança e adolescente, no sentido de prevenção da mendicância, trabalho precoce, prostituição e delinquência. 
Nesse sentido, o pediatra José Ricardo de Mello Brandão (2003), na pesquisa intitulada “Adolescente infratores em São Paulo: retrato da exclusão social?”, conclui que (...) "a maior parte dos meninos infratores tem um histórico de abandono ou expulsão do ambiente escolar. A escola é o elo perdido do adolescente infrator".

A transferência compulsória se caracteriza como uma medida disciplinar paliativa, não resolvendo satisfatória e nem adequadamente a questão. Torna-se imprescindível a elaboração do Projeto Pedagógico, Plano de Gestão e Regimento Escolar com a participação de todos os integrantes da comunidade escolar, estabelecendo previamente e, de forma clara, normas de conduta (direitos e deveres) não só dos alunos mas de todos os envolvidos na comunidade escolar, assim como, as respectivas medidas disciplinares, quando não cumpridas, além da indicação da instância encarregada da apreciação e aplicação das mesmas e que jamais importem na exclusão do aluno do sistema educacional e nem o submeta a situações de constrangimento e exclusão do processo educacional.

O Projeto Pedagógico, o Plano de Gestão e o Regimento Escolar deverão prever direitos e deveres dos gestores escolares, do corpo docente e discente, assim como, a sistemática de avaliação do ato de indisciplina do estudante e, na aplicação de eventual sanção, respeitar os princípios da legalidade, do contraditório e "ampla defesa" previstos da Constituição Federal. (Inciso XXXVIII do art. $5^{\circ}$ ), com o objetivo de inviabilizar os atos arbitrários e ilegais do estabelecimento escolar

\section{A FUNÇÃO SOCIAL PEDAGÓGICA E EDUCACIONAL DA ESCOLA}

Os dados relacionados à violência dentro e fora das escolas evidenciam que o respeito, fundamento da desejada convivência saudável, na prática vem sendo submetido a progressiva deterioração. Por isso, afinado com a sua missão de defesa da sociedade e de garantidor dos direitos da cidadania, o Ministério Público, por seu Conselho Nacional, e a Estratégia Nacional de Justiça e Segurança Pública (Enasp), em parceria com as unidades do Ministério Público nos Estados e no Distrito Federal e com as Secretarias de Estado da Educação, lançaram em 2014 a Campanha Conte até 10 nas Escolas, no intuito de estimular o debate junto aos alunos do ensino médio de todo o país, em torno do respeito e dos direitos e deveres dos jovens, partindo dos alarmantes índices de vitimização da população entre 15 a 24 anos por homicídios.

Educação, Psicologia e Interfaces, Volume 3, Número 3, p. 48-63, Setembro/Dezembro, 2019.

ISSN: 2594-5343. DOI: https://doi.org/10.37444/issn-2594-5343.v3i3.165 
Além da Cartilha com roteiros de aula sobre esses temas, soma-se um Guia Prático para Educadores, com vasta informação sobre diálogo e mediação de conflitos, bem como atividades sugeridas, detalhadamente descritas, para que o professor nos conflitos cotidianos encontre, em conjunto com esses jovens alunos, os caminhos para solucionálos, restabelecendo a tranquilidade na comunidade escolar e fortalecendo o vínculo de pertencimento ao grupo.

O Guia foi escrito pelo promotor de Justiça no Estado de São Paulo, Antonio Carlos Ozorio Nunes (2011), que também se viu diariamente desafiado em sala de aula, quando professor da rede pública de ensino por mais de sete anos, ao exercício das habilidades de escuta, comunicação, diálogo e solução consensuada de conflitos.

Essa experiência do autor foi exitosamente compartilhada com quase dez mil educadores da rede estadual de ensino paulista, por meio de cursos presenciais e à distância, e publicada em livro, no qual constam depoimentos de educadores que, estimulados pelas informações nele contidas protagonizaram, com o seu alunado, transformações extraordinárias no ambiente escolar, concretizando o respeito. Espera-se que cada educador, com a sua rica vivência em sala de aula, em escola da capital, cidade do interior o da zona rural, encontrem razão para perseverar na formação de cidadãos.

A concretização da dimensão pedagógica exige uma reeducação pedagógica da sociedade e um reordenamento das instituições sociais, entre as quais, a comunidade escolar nos marcos de uma pedagogia emancipadora, propiciando a relação dialógica, em lugar da valorização da sanção punitiva e excludente.

\section{CONTEXTUALIZAÇÃO DA INDISCIPLINA E DO ATO INFRACIONAL}

O Promotor de Justiça Luiz Antônio Miguel Ferreira (A indisciplina e o ato infracional s/d) entende que o ato de indisciplina se traduz em um desrespeito, 'seja do colega, seja do professor, seja ainda da própria instituição escolar, como depredação das instalações, por exemplo. Nem todo ato indisciplinar configura ato infracional. (Previsão legal mais intenção)”.

Ato Infracional é por ele considerado como conduta prevista como crime ou contravenção penal praticada por criança ou adolescente, podendo ser caracterizado como de menor potencial ofensivo (perturbar, injuriar, desrespeitar) ou de maior gravidade 
potencial ofensiva (furtar, lesionar, portar arma). As providências devem ser, neste caso da polícia e não da escola.

Uma ofensa verbal dirigida ao professor, pode ser caracterizada como ato de indisciplina. No entanto, dependendo do tipo de ofensa e da forma como foi dirigida, pode caracterizar ato infracional - ameaça, injúria ou difamação. Para cada caso, os encaminhamentos são diferentes. Segundo definição do ECA (art. 103), considera-se ato infracional a conduta descrita como crime ou contravenção penal.

Neste caso, toda conduta típica prevista no Código Penal, na Lei das Contravenções Penais e nas leis penais esparsas, quando praticada por criança ou adolescente, será considerada um ato infracional. $\mathrm{O}$ ato infracional é perfeitamente identificável na legislação vigente. Já o ato indisciplinar deve ser regulamentado, nas normas que regem a escola, assumindo o Regimento Escolar papel relevante para a questão.

Os casos de maior gravidade, a Direção da Escola deve conduzir à Delegacia de Polícia, com a presença de pais e ou responsáveis para que a autoridade policial, providencie a elaboração do boletim de ocorrência e a requisição dos laudos necessários à comprovação da materialidade do fato, imprescindível à instauração de processo contra o adolescente, visando a aplicação de medida socioeducativa. Deve-se evitar a policialização do dever de educar, ou seja, a entrada e permanência de policiais na escola.

$\mathrm{O}$ ato infracional pode ocorrer nas seguintes circunstâncias: lesão corporal em que a vítima apresenta sinais da agressão, em razão da necessidade de laudo de exame de corpo de delito; homicídio em que a vítima deve ser submetida a laudo de exame cadavérico; porte para uso ou tráfico de entorpecentes, pois a autoridade policial realizará a apreensão da droga e irá requisitar o laudo de exame químico toxicológico; porte de arma, tornando-se necessária a apreensão da mesma, que será submetida a exame pelo instituto de criminalística; porte de explosivos ou bomba caseira, sendo necessária, também, a apreensão do material que será objeto de exame pelo instituto de criminalística; dano intencional ao patrimônio público ou particular, em que deverá ser efetuado o levantamento do local.

$\mathrm{O}$ ato infracional não poderá ser narrado de modo genérico, mas sim detalhado. São necessárias: a) a qualificação completa do adolescente infrator (nome, filiação, data de nascimento, endereço); b) a indicação de data, horário e local do fato; c) o nome das

Educação, Psicologia e Interfaces, Volume 3, Número 3, p. 48-63, Setembro/Dezembro, 2019.

ISSN: 2594-5343. DOI: https://doi.org/10.37444/issn-2594-5343.v3i3.165 
vítimas (com qualificação completa); d) a informação de eventuais danos causados ao patrimônio da escola ou de terceiros; e) a indicação de testemunhas.

Se $\mathrm{o}$ ato infracional for praticado por criança (pessoa com até 12 anos incompletos), os fatos devem ser encaminhados ao Conselho Tutelar. No local em que os Conselhos Tutelares não estiverem em funcionamento, o encaminhamento deverá ser feito ao Juiz de Direito da Comarca e, na Capital, ao Juizado da Infância e Juventude, mediante ofício. Os casos de comportamento irregular e de indisciplina devem ser apreciados pela escola, que aplicará as sanções previstas no Regimento Escolar ou, em último caso, encaminhará ao Conselho Tutelar ou Promotoria de Justiça da Infância e Juventude para o devido acompanhamento. Enfatiza-se que deve ser assegurado em quaisquer circunstâncias, o direito ao contraditório e da ampla defesa conforme o amparo legal instituído na Constituição Brasileira de 1988:

\begin{abstract}
Art. $5^{\circ}$ Todos são iguais perante a lei, sem distinção de qualquer natureza, garantindo-se aos brasileiros e aos estrangeiros residentes no País a inviolabilidade do direito à vida, à liberdade, à igualdade, à segurança e à propriedade, nos termos seguintes (...):

LV - aos litigantes, em processo judicial ou administrativo, e aos acusados em geral são assegurados o contraditório e ampla defesa, com os meios e recursos a ela inerentes (...)
\end{abstract}

\title{
7. A TRANSFERÊNCIA COMPULSÓRIA NOS TERMOS DA INDICAÇÃO
} CEE 175/2019

Segundo notícia publica da no Jornal O Estado de São Paulo, em 2015 a Secretaria de Estado de Educação, organizou um grupo para avaliar a questão da transferência compulsória após inquérito aberto pelo Ministério Público Estadual. Conforme a publicação, a transferência compulsória nesse ano já estava vetada no Paraná e no Distrito Federal. No entanto, no estado de São Paulo não houve definição a respeito (TOLEDO, 2015).

A questão da transferência compulsória como "sanção disciplinar" voltou a ser discutida no Conselho Estadual de Educação em 2019 (Processo 2091086). O Conselho Estadual de Educação de São Paulo provocado pelo Ministério Público de São Paulo GEDUC (Grupo de Atuação Especial de Educação) e pela Secretaria de Estado da Educação, considerando as prerrogativas da LDBEN nº 9394/1996, que confere liberdade 
de organização aos Sistemas de Ensino (art. $8^{\circ}, \S 2^{\circ}$ ) e a incumbência dos estados para baixar normas complementares para o seu Sistema (art. 10, inciso V), voltou a se manifestar, nesse ano, sobre a inserção da transferência compulsória no Regimento Escolar, como "sanção" no título "referente as normas de gestão e convivência" (Processo 2091086).

No Diário Oficial do Estado de São Paulo (19/04/2019) foi publicada a Indicação CEE 175/2019 sobre a inserção da transferência compulsória no Regimento Escolar, como medida disciplinar de "caráter excepcional". A Conselheira Relatora Rosângela Aparecida Ferini Vargas Chede, na supracitada Indicação CEE em sua análise sobre a questão do "Regimento Escolar e o direito à educação e à aprendizagem", e "a transferência por questões disciplinares como medida educativa de caráter excepcional" alerta que já no ano 2000, o Conselheiro o Conselheiro Bahij Amin Aur evidenciava

\begin{abstract}
(...) a preocupação com o direito à Educação e alertava as escolas, em seu Parecer CEE/SP 101/2000, para a impossibilidade de medida disciplinar voltada para a "expulsão de alunos". A expulsão prejudicava a vida escolar pois não havia garantia da continuidade de estudos e, por vezes, gerava "estigmas e rótulos" à imagem dos adolescentes, dificultando a obtenção de uma nova vaga em outra Escola. Similarmente pode-se pensar que a "transferência compulsória", quando presente no Regimento Escolar e exercida de forma unilateral, pode representar prática excludente e punitiva(...).
\end{abstract}

\title{
9. CONSIDERAÇÕES FINAIS
}

Este artigo, reafirma a tese de que em situações de atos de violência grave e ou da prática de ato infracional por parte de crianças e adolescentes, a competência na solução, transcende a ação autônoma da escola e deve ser tomada em conjunto com o Conselho Tutelar ou com o Juiz da Comarca, onde não houver o Conselho Tutelar e, nos casos mais graves, com o Ministério Público.

O diálogo com a família e ou responsáveis, deve estar sempre presente em todas as situações de indisciplina ou ato infracional, assim como, a busca de apoio da rede de proteção da criança e do adolescente. Prioridade absoluta é o cumprimento dos direitos de acesso e permanência da criança e do adolescente prescritos na Constituição Federal e nos demais instrumentos legais vigentes

Educação, Psicologia e Interfaces, Volume 3, Número 3, p. 48-63, Setembro/Dezembro, 2019. 
Defende-se a tese do Promotor de Justiça do Estado do Paraná Murilo José Digiácomo em seu artigo Direitos do Aluno e a Indisciplina, publicado no blog de Sonia Aranha(s/d), que a aplicação das medidas disciplinares de suspensão previstas no Regimento Escolar, não deve ser entendida somente como a não frequência à escola mas, contemplar obrigatoriamente, a realização de atividades paralelas, nas próprias dependências da instituição escolar ou em outro local, desde que sob a supervisão de educadores, para que o aluno continue em seu processo ensino/aprendizagem e de formação para a cidadania responsável e participativa.

Com relação a transferência compulsória, a escola não deve reforçar o ato punitivo mas cumprir o seu papel social enquanto instituição que se propõe a educar para a cidadania e não apenas ao ensino/aprendizagem. Defende-se também que mediante a aplicação dessa medida, em hipótese alguma deverá permanecer fora do contexto escolar, até o julgamento final do recurso, se este for impetrado pelo aluno, pais ou responsáveis, evitando-se situações de constrangimento e exclusão.

\section{Notas de rodapé}

${ }^{1}$ Foi fundada logo após o fim da Segunda Guerra Mundial, com o objetivo de contribuir para a paz e segurança no mundo, por meio da educação, da ciência, da cultura e das comunicações.

${ }^{2}$ A BNCC para o Ensino Médio ainda está em análise.

${ }^{3}$ Estados, Municípios e Distrito Federal.

\section{REFERÊNCIAS BIBLIOGRÁFICAS}

ABRAMOVAY, Miriam et al. Diagnóstico participativo das violências nas escolas: falam os jovens. Rio de Janeiro, 2016. Disponível em: http:www.flacso.org.br/.../Diagnóstico-participativo-das-violências-nasescolas_COMPLETO: FLACSO, Brasil, OEI, MEC, 2016. 97 p. Acesso em: 05/04/2019.

ARENDT, Hannah. A condição humana. SP: Forense, 1972.

BRANDÃO, José Ricardo de Melo. Adolescente infratores em São Paulo: retrato da exclusão social? Permanecer na escola tira jovens do crime. Disponível em: http://www.uol.com.br ,14/10/ 2003. Acesso em 06/04/2019.

BRASIL. Conselho Nacional do Ministério Público. Diálogos e mediação de conflitos nas escolas. Guia Prático para Educadores. Brasília, 2014.Disponível em: http://www.cnmp.mp.br/.../6004-dialogos-e-mediacao-de-conflitos-nas-escolas-guiapratico Acesso em: 05/04/2019 
BRASIL. Base Nacional Comum Curricular. Educação é a base. Ministério da Educação, Brasília, 2017. Disponível em: http:// www.basenacionalcomum.mec.gov.br/ Acesso: 05/04/2019.

BRASIL. Constituição da República Federativa do Brasil de 1988 com alterações determinadas pelas Emendas Constitucionais e pelo Decreto Legislativo no 186/2008. Brasília: Senado Federal, Coordenação de Edições Técnicas, 2016.

Disponível em:

http://www2.senado.leg.br/bdsf/bitstream/handle/id/518231/CF88_Livro_EC91_2016.p df. Acesso: 06/04/2019

BRASIL. Lei de Diretrizes e Bases da Educação Nacional N. 9394/96. Atualizada Disponível em:

http://www2.senado.leg.br/bdsf/bitstream/handle/id/529732/lei_de_diretrizes_e_bases_ 1ed.pdf. Acesso: 05/04/2019

BRASIL. Estatuto da Criança e do Adolescente - ECA - Lei 8069/90. Disponível em: http://www.planalto.gov.br/ccivil_03/LEIS/L8069.htm. Acesso em 04/04/2019.

COSTA, Cândida. Dimensões da Medida Socioeducativa: entre o sancionatório e o pedagógico. Textos \& Contextos (Porto Alegre), v. 14, n. 1, p. 62 - 73, jan. /jun. 2015.

DIGIÁCOMO, Murilo José; ARANHA, Sonia. Direitos do aluno e a indisciplina. Disponível no blog de ARANHA, Sonia. Disponível em: http://www.soniaranha.com.br/direitos-do-aluno-e-a-indisciplina. s/d. Acesso: 25/04/2019.

DRABACH, Nádia Pedrotti. Gestão escolar democrática e gestão escolar gerencial: a confluência perversa. RS: UF de Santa Maria, 2010. (Monografia de Lato Sensu). Disponível em https://repositorio.ufsm.br/bitstream/handle/1/1657/Drabach_Nadia_Pedrotti.pdf?seque nce=1\&isAllowed=y Acesso: 03/04/2019.

DELORS, Jacques (org.) Educação - um tesouro a descobrir. Relatório para UNESCO da Comissão Internacional sobre Educação para o século XXI. São Paulo: Cortez; Brasília, DF: MEC: UNESCO, 2000.

HAHNE, Beatriz Saks. Sobre a indisciplina e o ato infracional: experiências escolares de alunos e professores. Dissertação de Mestrado. São Paulo: Instituto de Psicologia da Universidade de São Paulo, 2017.

FERREIRA, Luís Antônio Miguel. A indisciplina e o ato infracional. s/d, Disponível em: http://www.recriaprudente.org.br/site/abre_artigo.asp?c=1>Acesso 05/04/2019.

FREIRE, Paulo. Pedagogia da autonomia - saberes necessários à prática educativa. Rio de Janeiro: Paz e Terra, 2016.

LOPES, Marluce, SIMÕES, Marluce; SANTOS, Sérgio Pereira. Hannah Arendt e a educação: apontamentos e reflexões. Caderno de Prod. Acad.-Cient. Progr. PósGrad. Educ., Vitória-ES, v. 17, n. 2, jul. /dez. 2011. UFES, 2006. (Periódicos) 
Disponível em: http:/ www./periodicos.ufes.br/PRODISCENTE/article/view/5805 Acesso 06/04/2019.

LÜCK, H. Perspectivas da gestão escolar e implicações, quanto à formação de seus gestores. Em Aberto, v. 17, n. 72, p 1 -195, fev/ jun, 2000.

NUNES, Antonio Carlos Ozório. Como restaurar a paz nas escolas. Um Guia para Educadores. São Paulo: Saraiva, 2011.

SÃO PAULO. Conselho Estadual de Educação (CEE). Indicação CEE 175/2019. Regimento Escolar e o direito à educação e à aprendizagem: a transferência por questões disciplinares como medida educativa de caráter excepcional. Indicação 175/2019, aprovada pelo Conselho Pleno em 17/04/2019. Relatora: Cons. ${ }^{a}$ Rosângela Aparecida Ferini Vargas Chede. Diário Oficial do Estado de São Paulo - Poder Executivo. Sessão I. 19/04/2019, p.30-31.

SILVEIRA, Mayra. Ilegalidade da expulsão ou transferência compulsória de estudante. São Paulo: UFSC. 2014 Disponível em:

https://www.jus.com.br/artigos/28293/ilegalidade-da-expulsao-ou-transferenciacompulsoria-de-estudante. Acesso 04/04/2019

TOLEDO, Fernando Luiz. Rede paulista de ensino revê expulsão de alunos. São Paulo: Jornal O Estado de S. Paulo, 13/07/2015.

\section{Credenciais da autora}

MORRONE, Maria Lucia. Possui graduação em História pela Universidade de São Paulo e Pedagogia pela Faculdade Farias, mestrado em Educação pela Universidade de São Paulo e doutorado em Educação História Política Sociedade pela Pontifícia Universidade Católica de São Paulo. É professora titular da Universidade Ibirapuera. E-mail: morrone@uol.com.br

Endereço para correspondência: Maria Lucia Morrone.E-mail: morrone@uol.com.br

Como citar este artigo (Formato ABNT): MORROBE, Maria Lucia. Transferência compulsória no regimento escolar: um processo de exclusão na educação básica. Educação, Psicologia e Interfaces, v. 3, n.3, p. 48-63, 2019. DOI: https://doi.org/10.37444/issn-2594-5343.v3i3.165

Recebido: 07/08/2019.

Aceito: 20/11/2019. 